\title{
Kinetics of Tomato Peroxidase Inactivation by Atmospheric Pressure Cold Plasma Based on Dielectric Barrier Discharge
}

\author{
Patrick Cullen \\ Technological University of Dublin, pj.cullen@tudublin.ie \\ Shashi Pankaj \\ Technological University Dublin, shashi.pankaj@tudublin.ie \\ N. Misra \\ Technological University Dublin, misra.nrusimhanath@tudublin.ie
}

Follow this and additional works at: https://arrow.tudublin.ie/schfsehart

Part of the Chemical Engineering Commons, and the Food Chemistry Commons

\section{Recommended Citation \\ Cullen, P.J., Pankaj, S.K., Misra, N.N. : Kinetics of Tomato Peroxidase Inactivation by Atmospheric Pressure Cold Plasma Based on Dielectric Barrier Discharge, Innovative Food Science \& Emerging Technologies, Vol. 19, July 2013, pp. 153-157. doi.org/10.1016/j.ifset.2013.03.001.}

This Article is brought to you for free and open access by the School of Food Science and Environmental Health at ARROW@TU Dublin. It has been accepted for inclusion in Articles by an authorized administrator of ARROW@TU Dublin. For more information, please contact arrow.admin@tudublin.ie, aisling.coyne@tudublin.ie, gerard.connolly@tudublin.ie.

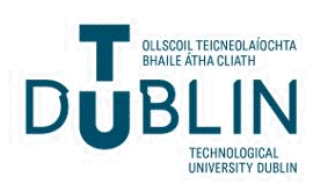


Kinetics of tomato peroxidase inactivation by atmospheric pressure cold plasma based on dielectric barrier discharge

S. K. Pankaj ${ }^{1}$, N. N. Misra ${ }^{1}$, P. J. Cullen ${ }^{1}$

${ }^{1}$ Bioplasma Group, School of Food Science and Environmental Health, Dublin Institute of Technology, Cathal Brugha Street, Dublin 1, Ireland

* Corresponding author-

P. J. Cullen; E-mail: pjcullen@dit.ie; Tel: +353 14024367 


\begin{abstract}
Atmospheric pressure cold plasma technology is an emerging nonthermal food technology for microbiological decontamination of food and bio-materials. This study demonstrates the applicability of in-package cold plasma technology as a novel means to inactivation of enzymes. The kinetics of inactivation of tomato peroxidase as a model enzyme was studied at 30, 40 and 50kV, for up to $5^{\prime}$ of atmospheric air dielectric barrier discharge plasma treatments. The enzyme activity was found to decrease with both treatment time and voltage, the former variable exhibiting a more pronounced effect. Kinetic models viz. first-order, Weibull and logistic models were fitted to the experimentally observed data to numerate the model parameters. The enzyme inactivation kinetics was found to be best described the sigmoidal logistic function.
\end{abstract}

\title{
Keywords
}

Cold Plasma, Nonthermal, Enzyme, Peroxidase, Tomato

\section{Industrial Relevance}

In-package cold plasma processing is a novel and innovative approach for the decontamination of foods with potential industrial application. This paper provides evidence for reduction of tomato peroxidase activity using cold plasma from a dielectric barrier discharge. It also demonstrates that the sigmoidal shaped logistic model adequately describes the enzymatic inhibition. The work described in this research is relevant to the processing of fruits, vegetables and their products, wherein enzyme activity leads to quality deterioration. 


\section{Introduction}

The inactivation of enzymes endogenous to fruits and vegetables is one of the most important aims of food preservation operations. The loss of quality parameters such as colour, flavour, texture and nutritional characteristics in raw, minimally or fully processed fruits and vegetables during storage as a consequence of the activity of residual endogenous enzymes is well recognised. For example, pectic enzymes particularly pectin methylesterase influence viscosity, cloud stability (Espachs-Barroso, Van Loey, Hendrickx, \& Martín-Belloso, 2006), polyphenol oxidases result in browning and off-colour development (McEvily, Iyengar, \& Otwell, 1992), while peroxidases catalyse peroxidation reactions, the end products of which can lead to off-flavour development in a number of food products.

To prevent unwanted changes during storage, fruit and vegetable products are generally subjected to suitable processing for inactivation of enzymes. Heat treatments such as blanching, pasteurization, or commercial sterilization are common conventional processes to achieve this (Anthon \& Barrett, 2002). Despite the fact that thermal processes can effectively inactivate enzymes, their detrimental impact on colour, flavour and nutritional quality of food products cannot be overlooked. The limitations of thermal processes have articulated the need of novel nonthermal technologies. The potential of nonthermal technologies to inactivate enzymes either alone or in combination with heat treatment is well documented through more than a decade's research. To cite an example, Cano, Hernandez, \& Ancos (1997) and Terefe, Yang, Knoerzer, Buckow, \& Versteeg (2010) have reported inactivation of peroxidase and polyphenol oxidase using high pressure processing. Likewise, Aguiló-Aguayo, Odriozola-Serrano, Quintão-Teixeira, \& Martín-Belloso (2008) and Elez-Martínez, et al. (2006) have reported inactivation of peroxidase during pulsed electric field processing. Effects of ultrasound processing on enzymes of importance to food processing have been studied by Lopez, Sala, de la Fuente, Condon, Raso, \& Burgos (1994), Ercan \& Soysal (2011) and reviewed in detail by O’Donnell, Tiwari, Bourke, \& Cullen (2010). 
However, the requirement of complex or expensive equipment (as for high pressure processing and pulsed electric field processing) or even difficulties encountered in development of suitable commercial scale equipment (e.g. ultrasound processing) for most nonthermal technologies cannot be overlooked. The need for a relatively simple to operate and cost-effective technology for processing of fresh produce and/or their products still persists.

Cold plasma is an emerging nonthermal food technology which has recently drawn considerable interest for decontamination of foods and food processing surfaces. The term "plasma" refers to a partially or wholly ionized gas composed essentially of photons, ions and free electrons as well as atoms in their fundamental or excited states possessing a net neutral charge (Misra et al., 2012). Depending on the relative energy levels of electrons and constituent species, plasmas are classified into thermal or nonthermal plasmas. Unlike thermal plasmas, nonthermal plasmas are characterised by disequilibrium of temperature between the electrons and ions (hence also referred to as non-equilibrium plasmas). Cold plasmas at atmospheric pressures can be generated using several techniques. Dielectric barrier discharge (DBD) is one such method which offers versatility in its mode of operation and system configuration. In DBD, plasma is generated between two electrodes, separated by one or more dielectric barriers. The dielectric material inhibits the transition to arc regime in a DBD.

Fundamentals of cold plasma technology and its applications to decontamination of foods have been reviewed by Misra, Tiwari, Raghavarao, \& Cullen (2011) and Niemira (2012). Unlike research for foodborne pathogen inactivation, no studies have been conducted to this end to evaluate the effect of DBD plasma on enzymes from fruit or vegetable sources. This general scarcity of information regarding inactivation of endogenous food enzymes in literature forms the motivation of the present work.

Plant peroxidases (POD, donor: hydrogen peroxide oxireductase, E.C.1.11.1.7) are commonly found in many fruits and vegetables. The presence of this enzyme has been found to have an empirical 
relationship to off-flavours and off-colours in raw and unblanched frozen vegetables (Ercan, et al., 2011). POD being one of the most heat stable enzymes is conventionally used as a marker to monitor and evaluate the extent of heat treatment (Gonçalves, Pinheiro, Abreu, Brandão, \& Silva, 2007; Williams, Lim, Chen, Pangborn, \& Whitaker, 1986). The specific aims of this work were (i) to evaluate the effects of atmospheric pressure DBD based cold plasma process variables upon activity of tomato peroxidase and (ii) model the kinetics of enzyme activity.

\section{Materials and Methods}

\section{Materials}

Fresh ripened tomatoes (Solanum lycopersium; Vine Tomato, Holland) were purchased from a local wholesale market (Smithfield, Dublin). Tomatoes had a pH of $4.25 \pm 0.10$, as measured with a calibrated glass electrode ORION pH meter (model 420A, Thermo Fisher Scientific Inc.), and a soluble solid content of $4.2 \pm 0.2^{\circ}$ Brix, as measured with a hand-held refractometer (Bellingham and Stanley Ltd., UK). The colour of the tomatoes were $L^{*}=48.45 \pm 1.38, a^{*}=29.41 \pm 2.85$ and $b^{*}=34.49 \pm 1.61$, recorded using a colorimeter (Colour Quest XE Hunter Lab, Northants, U.K.). Monosodium phosphate, Disodium phosphate, p-phenylenediamine and hydrogen peroxide were obtained from Sigma-Aldrich, Ireland.

\section{Preparation of crude extract}

Crude enzyme was extracted following the method used by Hemeda \& Klein (2006) with slight modifications. Tomatoes were washed and cut into small pieces and blended at high speed for 1 minute with $20 \%(\mathrm{w} / \mathrm{v})$ water addition at $4^{\circ} \mathrm{C}$. The homogenate was stirred for $15 \mathrm{~min}$ and then centrifuged at a relative centrifugal force of $13000 \mathrm{~g}$ for $30 \mathrm{~min}$ at $4^{\circ} \mathrm{C}$ with a centrifuge (Sanio MSE Mistral $3000 \mathrm{ii}$, UK). Supernatant solutions were collected and then filtered through Whatman No. 4 paper. The filtered solution constituted the enzyme extract and it was kept frozen at $-18^{\circ} \mathrm{C}$ until plasma treatments, which 
were carried out within $48 \mathrm{~h}$ of the extract preparation (Ercan, et al., 2011). Each experiment was run in two replicates ( $15 \mathrm{~mL}$ extract per run) and all measurements were performed at least in duplicate.

\section{Plasma treatment}



Figure 1 Schematic of the experimental setup for DBD plasma system.

A schematic of the experimental setup has been presented in Figure 1 and also described elsewhere (Ziuzina et al., 2013). Briefly, the DBD plasma source is comprised of two circular aluminium plate electrodes (outer diameter $=158 \mathrm{~mm}$ ) over polypropylene (PP) dielectric layers ( $2 \mathrm{~mm}$ thickness) between which a PP package containing the crude enzyme extract in a petriplate is placed. When the potential across the gap reaches the breakdown voltage the dielectric acts as a stabilizing material leading to the formation of a large number of micro-discharges. The discharge was obtained instantaneously at voltages above $28 \mathrm{kV}$ with the current experimental set-up. The applied voltage to the electrode, obtained from a step-up transformer (Phenix Technologies, Inc., USA) was regulated using a variac (supplied by the manufacturer of transformer). The primary winding of high voltage step-up transformer (Phenix Technologies, Inc., USA) obtained input from 230V, $50 \mathrm{~Hz}$ frequency mains supply. The rigid PP package had dimensions of $310 \mathrm{~mm} \times 230 \mathrm{~mm} \times 22 \mathrm{~mm}$ and also served as a dielectric 
material. In order to obtain a stable discharge, $2 \mathrm{~mm}$ thick polypropylene boards were used as dielectric barriers at either ends. The distance between the electrodes was $26 \mathrm{~mm}$. The atmospheric air condition at the time of treatment was $42 \%$ relative humidity $(\mathrm{RH})$ and $25^{\circ} \mathrm{C}$, as measured using humiditytemperature probe connected to a data logger (Testo 176 T2, Testo Ltd., UK).

\section{POD assay}

POD activity was measured using the method described by Cano, et al. (1997). POD activity was assayed spectrophotometrically by placing $2.7 \mathrm{~mL}$ of $0.05 \mathrm{M}$ sodium phosphate buffer $(\mathrm{pH}=6.5), 0.2 \mathrm{ml}$ of $\mathrm{p}$ phenylenediamine $(10 \mathrm{~g} / \mathrm{kg})$ as $\mathrm{H}$-donor, $0.1 \mathrm{ml}$ of hydrogen peroxide $(15 \mathrm{~g} / \mathrm{kg})$ as oxidant and $0.1 \mathrm{ml}$ of enzymatic extract in a $1 \mathrm{~cm}$ path cuvette. The oxidation of $\mathrm{p}$-phenylenediamine was measured at 485 $\mathrm{nm}$ and $25^{\circ} \mathrm{C}$ using a Shimadzu UV 1800 spectrophotometer (Shimadzu Scientific Instruments). POD activity was determined by measuring the initial rate of the reaction computed from the linear portion of the plotted curve. One unit of POD activity was defined as a change in absorbance at $485 \mathrm{~nm} \mathrm{~min}{ }^{-1}$ $\mathrm{ml}^{-1}$ of enzymatic extract.

\section{POD inactivation kinetics}

The percentage of residual POD activity $(R A)$ was defined by equation 1 :

$$
R A=\frac{A_{t}}{A_{0}} .100
$$

where $A_{t}$ and $A_{0}$ were the enzyme activities of treated and untreated samples, respectively. $\mathrm{A}_{\mathrm{t}}$ and $\mathrm{A}_{0}$ were determined immediately after plasma treatment to avoid any effect of storage time. Experimental data was modelled using a first-order inactivation model (equation2).

$$
R A=R A_{0} \cdot e^{-K_{P} \cdot t}
$$


The inactivation rate constant $K_{p}$ was obtained by least squares non-linear regression. The inactivation rate constant $K_{p}$ can also be obtained from the slope of the regression of $\ln (R A)$ compared with treatment time $(t, \mathrm{~min})$.

Weibull distribution (equation 3), was also fitted for investigation of the inactivation kinetics.

$$
R A_{t}=R A_{0} \cdot e^{-(t / \alpha)^{\gamma}}
$$

where, $R A(\%)$ is the residual activity of POD at time $t, R A_{0}(\%)$ is the residual activity without any treatment $(100 \%), t$ is the treatment time $(\min ), \alpha$ is the scale factor $(\min )$ and $\gamma$ is the shape parameter(dimensionless) which indicates concavity or convexity of the curve. From the Weibull distribution function parameters $(\alpha, Y), t_{m}$ can be derived by equation 4 which is the mean processing time to achieve complete POD inactivation.

$$
t_{m}=\alpha \cdot \Gamma \cdot(1+1 / \gamma)
$$

where, $\alpha$ and $Y$ are the parameters of the Weibull distribution and $\Gamma$ is the gamma function. It is to be noted that Weibull model was first employed to describe destruction kinetics of microorganisms, but has also been used for studying enzyme inactivation kinetics (Elez-Martínez, et al., 2006; Giner, et al., 2005; Odriozola-Serrano, Soliva-Fortuny, Gimeno-Añó, \& Martín-Belloso, 2008) for other nonthermal technologies.

In addition to first order and Weibull model, a three parameter logistic model, presented in equation 5, was also evaluated, considering the visual shape of data. 


$$
R A=\frac{\left(100-A_{\min }\right)}{1+\left(\frac{t}{t_{50}}\right)^{p}}+A_{\min }
$$

where, $A_{\min }(\geq 0)$ is the minimum value attained by the logistic function, $t_{50}$ is the time for half maximal activity and $p$ is the power term. This equation represents a sigmoidal type of inactivation curve.

\section{Statistical Analysis}

The effect of treatment time and treatment voltage on residual activity of peroxidase was statistically explored by Tukey's test in SPSS 19.0 (SPPS Inc., Chicago, IL, USA). The model parameters for all equations were estimated by non-linear least squares regression using Gauss-Newton algorithm available in Statistica software (Statistica 7.0, Statsoft, Tulsa, OK, USA). The goodness of fit was assessed based on the adjusted coefficient of determination, $R^{2}$ (adj) given in equation 6 along with an analysis of residuals.

$$
R_{a d j}^{2}=1-\left(\frac{n_{t}-1}{n_{t}-n_{p}}\right) \cdot \frac{S S E}{S S T O}
$$

Herein, SSTO is the total sum of squared errors and SSE the sum of squared errors,

$$
\text { . The root mean squared error (RMSE) was used as a criterion to evaluate the }
$$

adequacy of model fittings (equation 7).

$$
R M S E=\sqrt{\sum_{i=1}^{n_{t}} \frac{y_{\exp i}-y_{p r e d}^{2}}{n_{t}-n_{p}}}
$$

where $y_{\text {exp } i}$ are experimental observations, $y_{\text {pred }}$ are model predictions, $n_{t}$ are number of experimental data points and $n_{p}$ are number of estimated model parameters.

\section{Result and Discussion}




\section{Effect of voltage and treatment time on POD activity}

DBD plasma treatments were significantly $(p<0.05)$ effective in reducing the POD activity. Since temperatures that could have caused thermal inactivation of the enzyme were never reached, the inactivation that was observed was attributed to DBD plasma treatment alone. This was confirmed by recording the temperature rise using a handheld infrared thermometer (Maplin Electronics, UK), which recorded a maximum temperature rise of only $5{ }^{\circ} \mathrm{C}$ for all experiments. Treatment times and voltage both were found to have a significant effect $(p \leq 0.05)$ on residual activity of peroxidase. There was a significant difference in residual activity for all three applied voltages at $95 \%$ level of confidence. The interaction between voltage and time was also found to be significant $(p \leq 0.05)$.

\section{First-order kinetic model}

The inactivation rate constants $\left(K_{p}\right)$ were calculated from the slope of the lines and are summarised in Table 1 along with the regression coefficients for first-order kinetic model at the different voltage levels. It can be observed that although the $R^{2}$ values are high enough (0.99), the RMSE values are not satisfactory. Therefore, first-order model was considered inefficient in describing the POD residual activity. Moreover, in view of the complexity of the structure of an enzyme and the possible variety of different phenomena involved in the inactivation, the assumption that the disruption of a single bond or structure is sufficient to inactivate the enzyme, as proposed in first-order kinetics seems to be exceedingly simple (Adams, 1991). 
Table 1. Results on the parameters of the models fitted to inactivation kinetics of POD enzyme.

\begin{tabular}{lllll}
\hline Model & Parameter & \multicolumn{2}{l}{ Estimated Value } \\
\cline { 3 - 5 } & & $\mathbf{3 0 k V}$ & $\mathbf{4 0 k V}$ & $\mathbf{5 0 k V}$ \\
\hline First Order & $K_{p}\left(\mathrm{~min}^{-1}\right)$ & $0.63 \pm 0.06$ & $0.71 \pm 0.07$ & $0.99 \pm 0.05$ \\
& $R^{2}($ adj. $)$ & 0.94 & 0.95 & 0.99 \\
& $R M S E$ & 9.14 & 9.00 & 3.63 \\
\hline Weibull & $\alpha(\min )^{a}$ & $1.64 \pm 0.05$ & $1.52 \pm 0.03$ & $1.09 \pm 0.02$ \\
& $Y^{a}$ & $2.00 \pm 0.16$ & $2.00 \pm 0.08$ & $1.48 \pm 0.07$ \\
& $R^{2}$ & 0.99 & 0.99 & 0.99 \\
& $R M S E$ & 3.53 & 1.79 & 1.44 \\
\hline Logistic & $A^{a}{ }_{\min }$ & $2.20 \pm 0.56$ & $0.00 \pm 0.89$ & $0.00 \pm 0.99$ \\
& $t^{a}{ }^{a}$ & $1.29 \pm 0.012$ & $1.23 \pm 0.02$ & $0.89 \pm 0.02$ \\
& $P^{a}$ & $3.42 \pm 0.09$ & $3.29 \pm 0.15$ & $2.94 \pm 0.28$ \\
& $R^{2}$ & 0.99 & 0.99 & 0.99 \\
& $R M S E$ & 0.93 & 1.46 & 1.54 \\
\hline
\end{tabular}

$R^{2}=$ regression coefficients; a = Value \pm Standard Error

Model based on Weibull Distribution

The scale parameter $(\alpha)$ and shape parameter $(Y)$ of the Weibull model were obtained by fitting

experimental data to equation 3. The estimates of $\alpha$ and $Y$ along with $R^{2}$ values are listed in Table 1 . The Weibull model exhibited a strong fit to predict residual POD activity after DBD plasma treatments as indicated by the high coefficient obtained $\left(R^{2} \geq 0.99\right)$ for all voltage levels studied in this experiment. The scale parameter ranged from 1.09 to 1.64 , and exhibited an inverse dependency on voltage levels i.e. higher the applied voltage level, lower will be the scale parameter obtained. The shape parameter ranged from 1.48 to 2.00 . Figure 2 shows the fitted curves of the Weibull model at different voltage levels. It can be clearly observed that Weibull fit could not account for the tailing observed at 30kV treatment voltage, which is also obvious from the corresponding higher RMSE value. Therefore, a logistic model was proposed for further explanation. 


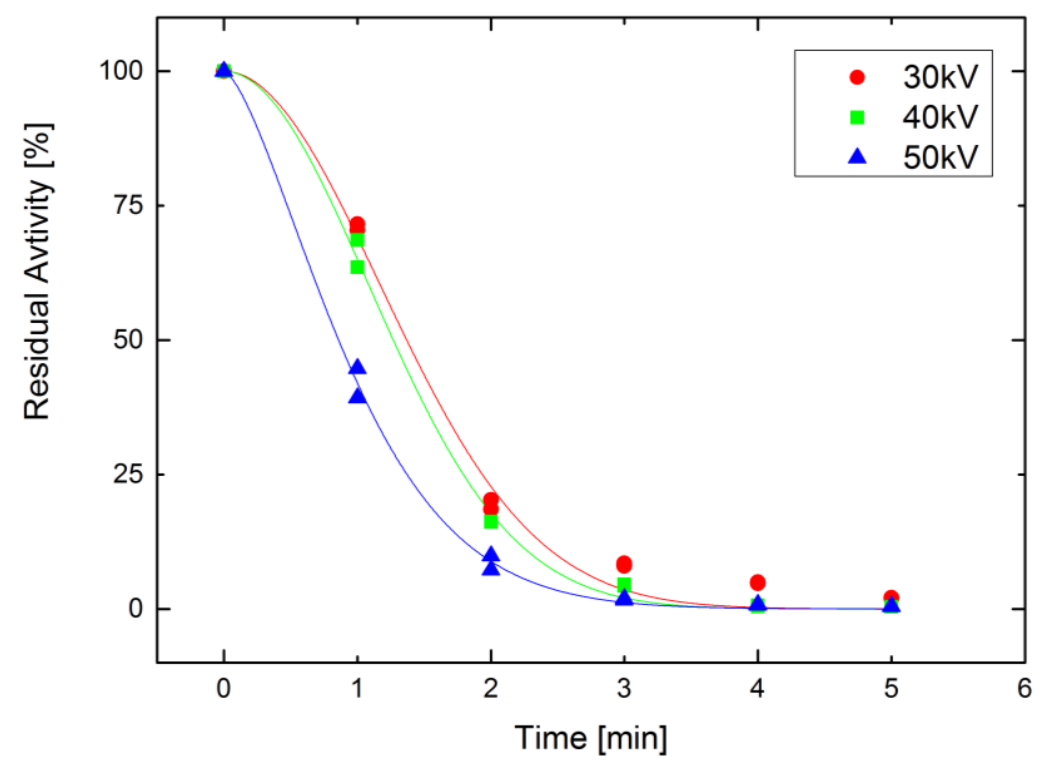

Figure 2 Weibull model curve fitting at different voltage levels for POD residual activity

\section{Logistic model}

The characteristic parameters of the Logistic model for POD inactivation were obtained from the experimental data fitted to equation 5 and shown in Figure 3. Estimates of parameters were significant at $\mathrm{p} \leq 0.05$ and $R^{2}$ value indicated that this model explained $99 \%$ of the variability in $R A$. The $A_{\min }$ value of $2.20 \pm 0.56$ for $30 \mathrm{kV}$ treatment explained the observed tailing effect. A $t_{50}$ value of 0.89 min accounted for the rapid POD inactivation at $50 \mathrm{kV}$ compared to 30 and $40 \mathrm{kV}$ treatments. Thus, it was concluded that the POD inactivation followed a sigmoidal inactivation, which can be explained by the logistic type model. 


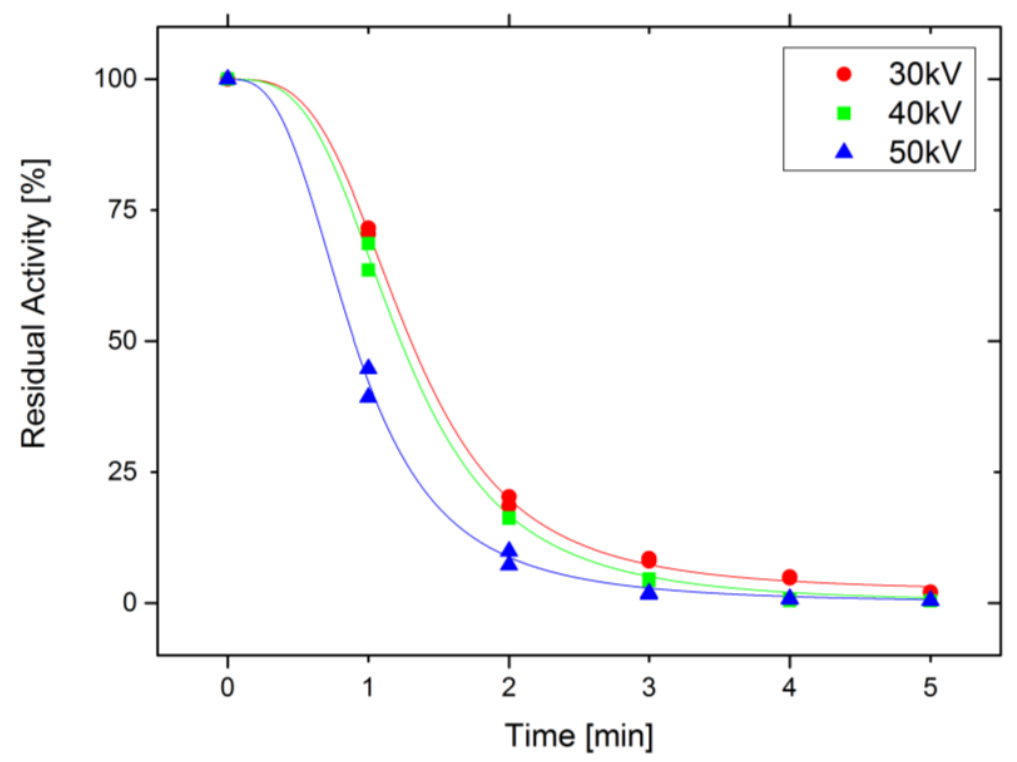

Figure 3 Logistic model curve fitting at different voltage levels for POD residual activity

We observed a general lack of published work on effects of DBD plasma on enzyme systems from fruit and vegetable sources. Therefore, the proposed mechanisms of inactivation were based on the works done on egg white lysozyme using low frequency helium plasma jet system by Takai, Kitano, Kuwabara, \& Shiraki (2012) and nitrogen-oxygen plasma by Bernard, Leduc et al. (2006). The authors have attributed the decrease in the enzyme activity to a change in the secondary protein structure and modification of some amino acids side chains of the enzymes. In a former study on exposure of lipase derived from Candida rugosa (Type VII, L-1754) to radio-frequency, atmospheric-pressure glow discharge Helium plasma jet an increase in the lipase activity was reported (Li, et al., 2011). Irrespective of the positive or negative effects on enzyme activity, this was also assigned to the changes in secondary and tertiary structure of protein by the reactive species of the plasma discharge. The study of effect of atmospheric pressure glow discharge plasma on bovine serum albumin has also confirmed the degradation of protein integrity (Deng, Shi, Chen, \& Kong, 2007) upon plasma treatment. One possible mechanism of reaction between plasma generated reactive species and protein suggested by Takai, et al. (2012) is that hydroxyl radicals $\left(\mathrm{OH}^{\circ}\right)$, superoxide anion radicals $\left(\mathrm{O}_{2}^{-\bullet}\right)$, hydroperoxy radicals $\left(\mathrm{HOO}^{\circ}\right)$ 
and nitric oxide $\left(\mathrm{NO}^{\circ}\right)$ leads to the chemical modifications of chemically reactive side-chain of the amino acids, such as cysteine, aromatic rings of phenylalanine, tyrosine, and tryptophan causing loss of enzyme activity. Similar mechanism for decomposition of $\mathrm{C}-\mathrm{H}, \mathrm{C}-\mathrm{N}$ and $\mathrm{N}-\mathrm{H}$ bonds of protein is also described by Hayashi, Kawaguchi et al. (2009). The DBD employed in the present study also generates reactive nitrogen species and primarily ozone when humid air is used as operating gas (Misra, Ziuzina, Cullen, \& Keener, 2012). By analogy, it is intuitive to believe that DBD plasma operating in atmospheric air causes changes in POD in enzyme extract through similar action of the species formed in the liquid media by diffusion from the gas phase plasma. However, further research is desired to deduce a global mechanism of enzyme inactivation under the influence of DBD cold plasma.

\section{Conclusion}

The effect of atmospheric cold plasma generated inside a sealed package on enzyme activity as a function of voltage and treatment time is reported. Treatment voltage and time were both found to have a significant effect on POD inactivation. The kinetic of inactivation were modelled using first-order, Weibull, and Logistic models. Treatment conditions were found to influence the inactivation rates and the shape of the inactivation curve, with tailing evident at the lowest voltage employed. The results from this study indicate that cold plasma can inactivate enzymes, in addition to the reported studies on microbial inactivation. However the mechanisms of action of cold plasma on POD and other enzyme inactivation requires further investigation.

\section{Acknowledgements}

The authors also acknowledge support from the Irish Research Council (IRC).

\section{References}


Adams, J. B. (1991). Review: Enzyme inactivation during heat processing of food-stuffs. International Journal of Food Science and Technology, 26, 1-20.

Aguiló-Aguayo, I., Odriozola-Serrano, I., Quintão-Teixeira, L. J., \& Martín-Belloso, O. (2008). Inactivation of tomato juice peroxidase by high-intensity pulsed electric fields as affected by process conditions. Food Chemistry, 107(2), 949-955.

Anthon, G. E., \& Barrett, D. M. (2002). Kinetic parameters for the thermal inactivation of quality-related enzymes in carrots and potatoes. Journal of agricultural and food chemistry, 50(14), 4119-4125.

Bernard, C., A. Leduc, et al. (2006). "Validation of cold plasma treatment for protein inactivation: a surface plasmon resonance-based biosensor study." Journal of Physics D: Applied Physics 39(16): 3470.

Cano, M., Hernandez, A., \& Ancos, B. (1997). High pressure and temperature effects on enzyme inactivation in strawberry and orange products. Journal of Food Science, 62(1), 85-88.

Deng, X., Shi, J., Chen, H., \& Kong, M. G. (2007). Protein destruction by atmospheric pressure glow discharges. Applied physics letters, 90(1), 013903.

Elez-Martínez, P., Aguiló-Aguayo, I., \& Martín-Belloso, O. (2006). Inactivation of orange juice peroxidase by high-intensity pulsed electric fields as influenced by process parameters. Journal of the Science of Food and Agriculture, 86(1), 71-81.

Ercan, S. S., \& Soysal, C. (2011). Effect of ultrasound and temperature on tomato peroxidase. Ultrason Sonochem, 18(2), 689-695.

Espachs-Barroso, A., Van Loey, A., Hendrickx, M., \& Martín-Belloso, O. (2006). Inactivation of plant pectin methylesterase by thermal or high intensity pulsed electric field treatments. Innovative Food Science \& Emerging Technologies, 7(1-2), 40-48.

Gonçalves, E. M., Pinheiro, J., Abreu, M., Brandão, T. R. S., \& Silva, C. L. M. (2007). Modelling the kinetics of peroxidase inactivation, colour and texture changes of pumpkin (Cucurbita maxima L.) during blanching. Journal of Food Engineering, 81(4), 693-701.

Hayashi, N., R. Kawaguchi, et al. (2009). "Treatment of Protein Using Oxygen Plasma Produced by RF Discharge." J. Plasma Fusion Res. Series 8: 552-555.Hemeda, H., \& Klein, B. (2006). Effects of naturally occurring antioxidants on peroxidase activity of vegetable extracts. Journal of Food Science, 55(1), 184-185.

Li, H. P., Wang, L. Y., Li, G., Jin, L. H., Le, P. S., Zhao, H. X., Xing, X. H., \& Bao, C. Y. (2011). Manipulation of Lipase Activity by the Helium Radio-Frequency, Atmospheric-Pressure Glow Discharge Plasma Jet. Plasma Processes and Polymers, 8(3), 224-229.

Lopez, P., Sala, F. J., de la Fuente, J. L., Condon, S., Raso, J., \& Burgos, J. (1994). Inactivation of peroxidase, lipoxygenase, and polyphenol oxidase by manothermosonication. Journal of agricultural and food chemistry, 42(2), 252-256. 
McEvily, A. J., lyengar, R., \& Otwell, W. S. (1992). Inhibition of enzymatic browning in foods and beverages. Critical Reviews in Food Science \& Nutrition, 32(3), 253-273.

Misra, N., Tiwari, B., Raghavarao, K. S. M. S., \& Cullen, P. (2011). Nonthermal Plasma Inactivation of Food-Borne Pathogens. Food Engineering Reviews, 1-12.

Misra, N. N., Ziuzina, D., Cullen, P. J., \& Keener, K. M. (2012). Characterization of a novel cold atmospheric air plasma system for treatment of packaged liquid food products. In $A S A B E$ Annual Meeting. Dallas, Texas: American Society of Agricultural and Biological Engineers.

Niemira, B. A. (2012). Cold Plasma Decontamination of Foods. Annual Review of Food Science and Technology, 3(1), 125-142.

O’Donnell, C. P., Tiwari, B. K., Bourke, P., \& Cullen, P. J. (2010). Effect of ultrasonic processing on food enzymes of industrial importance. Trends in Food Science and Technology, 21(7), 358-367.

Odriozola-Serrano, I., Soliva-Fortuny, R., Gimeno-Añó, V., \& Martín-Belloso, O. (2008). Modeling changes in health-related compounds of tomato juice treated by high-intensity pulsed electric fields. Journal of Food Engineering, 89(2), 210-216.

Takai, E., Kitano, K., Kuwabara, J., \& Shiraki, K. (2012). Protein Inactivation by Low-temperature Atmospheric Pressure Plasma in Aqueous Solution. Plasma Processes and Polymers, 9(1), 77-82.

Terefe, N. S., Yang, Y. H., Knoerzer, K., Buckow, R., \& Versteeg, C. (2010). High pressure and thermal inactivation kinetics of polyphenol oxidase and peroxidase in strawberry puree. Innovative Food Science \& Emerging Technologies, 11(1), 52-60.

Williams, D., Lim, M., Chen, A., Pangborn, R., \& Whitaker, J. (1986). Blanching of vegetables for freezing: Which indicator enzyme to choose. Food Technology, 40(6), 130-140.

Ziuzina, D., Patil, S., Bourke, P., Cullen, P. J., \& Keener, K. M. (2013). Atmospheric cold plasma inactivation of Escherichia coli in liquid media inside a sealed package. Journal of Applied Microbiology (doi: 10.1111/jam.12087). 